\title{
MODELAGEM DA DIFUSIVIDADE EFETIVA EM CASCA E POLPA DO ABRICÓ (Mammea americana) SUBMETIDAS A SECAGEM EM DIFERENTES TEMPERATURAS
}

\author{
D. C. SILVA ${ }^{1}$, M. F. LIMA ${ }^{1}$, T. J. SANTOS ${ }^{1}$, A. A. SANTANA ${ }^{1}$ e H. A. V. VELLEZ \\ ${ }^{1}$ Universidade Federal do Maranhão, Centro de Ciências Exatas e suas Tecnologias, \\ Departamento de Engenharia Química \\ E-mail para contato: dennys.correia@hotmail.com; harveyvilla@gmail.com
}

\begin{abstract}
RESUMO - O objetivo do presente trabalho foi a obtenção das curvas de secagem, o ajuste do modelo da difusão líquida e a determinação dos coeficientes de difusão de folhas da casca e polpa da fruta abricó (Mammea americana), submetidas a diferentes temperaturas do ar de secagem. Para uma eventual comparação dos resultados, realizaram-se os tratamentos de secagem com três níveis de temperatura do ar de secagem $\left(40,50\right.$ e $\left.60^{\circ} \mathrm{C}\right)$. Os valores da difusividade efetiva obtidos variaram $1,20 \times 10^{-04}$ a $5,95 \times 10^{-04} \mathrm{~mm}^{2} \mathrm{~s}^{-1}$ e $1,40 \mathrm{x}$ $10^{-04}$ a $3,50 \times 10^{-04} \mathrm{~mm}^{2} \mathrm{~s}^{-1}$ para a casca e polpa do abricó, respectivamente. A difusividade aumentou com o aumento da temperatura do ar de secagem e a energia de ativação para a difusão líquida variou de $3,061 \mathrm{KJ} \mathrm{mol}^{-1}$ para a casca do abricó e 3,979 $\mathrm{KJ} \mathrm{mol}^{-1}$ para a polpa do mesmo além de erros relativos médios abaixo de 0,1 .
\end{abstract}

\section{INTRODUÇÃO}

De nome científico Mammea americana, o abricó também pode ser conhecido como abricó-do-pará, abricote e abricoteiro. Seu fruto é carnoso, possui somente uma semente, é duro e redondo. É consumido principalmente nos Estados Unidos, e no Brasil, é mais consumido no estado do Pará. A árvore é frondosa, grande e piramidal e pode chegar aos 15 metros de altura. As folhas podem medir até $14 \mathrm{~cm}$ de comprimento, e são pecioladas. As flores são brancas, perfumadas e aparecem solitárias ou em pares opostos (PETRIN, 2016).

Por se tratar de uma fruta ainda silvestre a colheita ainda tem caráter extrativista, e, depois da coleta os frutos são repassados para intermediários a um baixo custo e revendidos em mercados maiores a um valor mais elevado. No atual cenário, a demanda é pequena e destinada apenas aos consumidores locais (BRAGA et al., 2010). Apesar de o congelamento ser o método mais clássico de conservação da polpa, o acondicionamento pela secagem também pode ser considerado por se basear no fato de que tanto os microrganismos como as enzimas e todo o mecanismo metabólico necessitam de certa quantidade de água para suas atividades. Com a redução da água disponível, consequentemente serão reduzidas a atividade de água e a velocidade das reações químicas no produto, bem como o desenvolvimento de microrganismos (MARTINAZZO et al., 2007; VASCONCELOS, 2015). 
O processo de secagem é uma técnica antiga para conservação de alimentos, tratando-se da remoção de água ou qualquer outro líquido do alimento na forma de vapor para o ar não saturado. Esta técnica vem sendo constantemente estudada e aperfeiçoada para obtenção de produtos com maior qualidade e menor tempo de processamento. É também uma das operações mais complexas e menos entendida, devido à dificuldade e deficiência da descrição matemática dos fenômenos envolvidos de transferência simultânea de calor, massa e quantidade de movimento no sólido. Assim a secagem é um conjunto de ciência, tecnologia e arte, ou seja, um know-how baseado em extensiva observação experimental e experiência operacional (MENON; MUJUMDAR, 1987). Este trabalho teve por finalidade determinar e avaliar a difusividade da umidade durante a desidratação da polpa e casca de abricó em diferentes temperaturas de secagem.

\section{MATERIAS E MÉTODOS}

\subsection{Matérias-Primas}

Os frutos de abricó foram adquiridos no Centro Estadual de abastecimento S/A (CEASA) da cidade de São Luís (MA). Para a realização dos experimentos os frutos foram lavados com solução sanitizante, retirando-se as partes doentes e danificadas, assim como qualquer parte de outro vegetal ou material estranho. Uma vez limpo o fruto, foi retirada a casca da polpa com ajuda de uma faca e, após, foram formadas pequenas placas retangulares com medidas $6,0 \times 2,5 \times 0,21 \mathrm{~cm}$ e $6,0 \times 2,5 \times 0,3 \mathrm{~cm}$ para a casca e polpa respectivamente. Assim, as placas de casca e polpa de abricó foram usadas para os experimentos de secagem. Para cada ensaio experimental de secagem foram usadas três amostras de cada material.

\subsection{Procedimento Experimental}

A secagem para a casca e polpa de abricó foi realizada em uma estufa de ar convectivo às temperaturas de 40,50 e $60{ }^{\circ} \mathrm{C}$. Para cada condição experimental de temperatura de secagem, foram realizadas pesagens periódicas em balança semi-analítica (precisão 0,001 g) até atingir-se massa constante, conforme o método de Silva et al. (2016). Uma vez terminado cada experimento, a umidade do sólido foi determinada por gravimetria usando estufa a vácuo a $105^{\circ} \mathrm{C}$ durante $24 \mathrm{~h}$, sendo que as curvas de secagem foram expressas em função do teor de água em base seca "b.s.".

Para o cálculo da razão de umidade (RU), durante a secagem nas diferentes condições de ar, utilizou-se a Equação (1).

$$
R U=\frac{X-X_{e}}{X_{o}-X_{e}}
$$

onde X é o teor de umidade no tempo de secagem (g/g, b.s.); Xe é o teor de umidade de equilíbrio (g/g, b.s.); X0 é o teor de umidade inicial (g/g, b.s.).

Para o cálculo da difusividade efetiva $\left(D_{e f f}, \mathrm{~mm}^{2} \mathrm{~s}^{-1}\right)$, foi utilizada a Eq. (2) derivada da solução analítica baseada na Lei de Fick, com espessura de corte L de 0,21 cm para a casca e $0,3 \mathrm{~cm}$ para a polpa (espessura do produto). Realizou-se análise de regressão não linear, pelo 
método Simplex e Quasi-Newton, utilizando-se o programa computacional statistica 7.0. A solução analítica da Equação (2) apresenta-se na forma de uma série infinita e, portanto, o número finito de termos (n) no truncamento pode determinar a precisão dos resultados (MARTINAZZO et al., 2007), com as seguintes condições inicial e de contorno (CRANK, 1975): umidade inicial uniforme (Equação (3)), umidade máxima no centro (Equação (4)) e umidade constante na superfície (Equação (5)).

$$
\begin{aligned}
& R U=\frac{8}{\pi^{2}} \sum_{n=0}^{\infty} \frac{1}{(2 n+1)^{2}} \exp \left[-(2 n+1)^{2} \pi^{2} D_{e f f} \frac{t}{4 L^{2}}\right] \\
& X_{(x, t)}=X_{(x, 0)}=X_{0} \\
& \frac{\partial X}{\partial x}(x=0)=0 \\
& X_{(x, t)}=X_{(L, t)}=X_{e}
\end{aligned}
$$

A variação do coeficiente de difusão de acordo com a temperatura de secagem foi analisada utilizando-se a relação de Arrhenius (Equação (6)). É usual considerar-se o valor do coeficiente de difusão constante ou linearmente dependente da temperatura, podendo essa relação ser expressa por meio deste modelo.

$$
D_{e f f}=A \exp \left(-\frac{E_{a}}{R T}\right)
$$

onde $A$ é o fator pré exponencial $\left(\mathrm{m}^{2} \mathrm{~s}^{-1}\right), E_{a}$ é a energia de ativação $\left(\mathrm{J} \mathrm{mol}^{-1}\right), R$ é a constante universal dos gases $\left(8,314 \mathrm{~J} \mathrm{~mol}^{-1} \mathrm{~K}^{-1}\right)$ e $T$ é a temperatura absoluta (K).

Para a modelagem e simulação foi avaliado o grau de ajuste do modelo aos dados experimentais em função da magnitude do coeficiente de determinação ajustado $\left(R^{2}\right)$ e do erro médio estimado (MRE) (\%) (Equação (7)).

$$
M R E=\frac{100}{N} \sum_{i=1}^{N} \frac{\left|X_{i}-X_{i}^{*}\right|}{X_{i}}
$$

Em que: $X_{i}$ é o valor observado experimentalmente; $X_{i}^{*}$ é o valor calculado pelo modelo e $N$ é o número de valores experimentais. Além disso, com o intuito de analisar o erro de ajuste $\left(e_{t}\right)$ do modelo estatístico foi realizada a comparação entre os resultados experimentais e calculados pelo modelo $\left(X_{c a l}\right)$, conforme a Equação (8).

$$
e_{t}=X_{i}-X_{i}^{*}
$$




\section{RESULTADOS E DISCUSSÃO}

Os valores da difusividade efetiva $\left(D_{\text {eff }}\right)$ obtidos para os diferentes tratamentos estão apresentados na Tabela 1, como também as medidas de ajuste do modelo (erro relativo médio, $M R E$, e coeficiente de determinação, $R^{2}$ ), o qual foi ajustado aos dados obtidos pela Eq. (2) com aproximação de dez termos, a partir do qual se observou que o valor de $D_{\text {eff }}$ não variava.

Tabela 1 - Valores da difusividade efetiva $\left(D_{e f f}\right)$ obtidos para a casca e a polpa do abricó em diferentes temperaturas do ar de secagem.

\begin{tabular}{|c|c|c|c|c|c|c|}
\hline \multirow{2}{*}{ Temperatura $\left({ }^{\circ} \mathrm{C}\right)$} & \multicolumn{3}{|c|}{ Casca } & \multicolumn{3}{c|}{ Polpa } \\
\cline { 2 - 7 } & $\begin{array}{c}\text { Difusividade } \\
\left(\mathrm{mm}^{2} \mathrm{~s}^{-1}\right)\end{array}$ & MRE (\%) & $\mathrm{R}^{2}$ & $\begin{array}{c}\text { Difusividade } \\
\left(\mathrm{mm}^{2} \mathrm{~s}^{-1}\right)\end{array}$ & MRE (\%) & $\mathrm{R}^{2}$ \\
\hline \hline $40^{\circ} \mathrm{C}$ & $5,95 \times 10^{-04}$ & 0,255 & 0,983 & $1,40 \times 10^{-04}$ & 5,722 & 0,847 \\
\hline $50^{\circ} \mathrm{C}$ & $9,04 \times 10^{-04}$ & 0,494 & 0,920 & $2,69 \times 10^{-04}$ & 2,159 & 0,971 \\
\hline $60^{\circ} \mathrm{C}$ & $12,0 \times 10^{-04}$ & 0,079 & 0,912 & $3,50 \times 10^{-04}$ & 4,183 & 0,988 \\
\hline
\end{tabular}

Observa-se que os valores de difusividade variaram de $1,20 \times 10^{-4}$ a $5,95 \times 10^{-4} \mathrm{~m}^{2} \mathrm{~s}^{-1} \mathrm{e}$ $1,40 \times 10^{-4}$ a $3,50 \times 10^{-4} \mathrm{~m}^{2} \mathrm{~s}^{-1}$ na faixa de temperatura de 40 a $60{ }^{\circ} \mathrm{C}$ para a casca e polpa do abricó, respectivamente. Segundo Rizvi (1986) e Martinazzo et al. (2007), a difusividade efetiva depende das características do ar de secagem e das demais propriedades físicoquímicas do material que se relacionam à espécie e à variedade. Os valores calculados de $D_{\text {eff }}$ para cada temperatura estão apresentados na Figura 1 na forma de "In D" plotados em função do inverso da temperatura absoluta $(1 / \mathrm{T})$. As retas obtidas indicam a uniformidade de variação da difusividade com a variação da temperatura.

Figura 1 - Representação de Arrhenius para a relação entre a difusividade efetiva e a temperatura absoluta para cada temperatura de secagem da casca e da polpa do abricó.

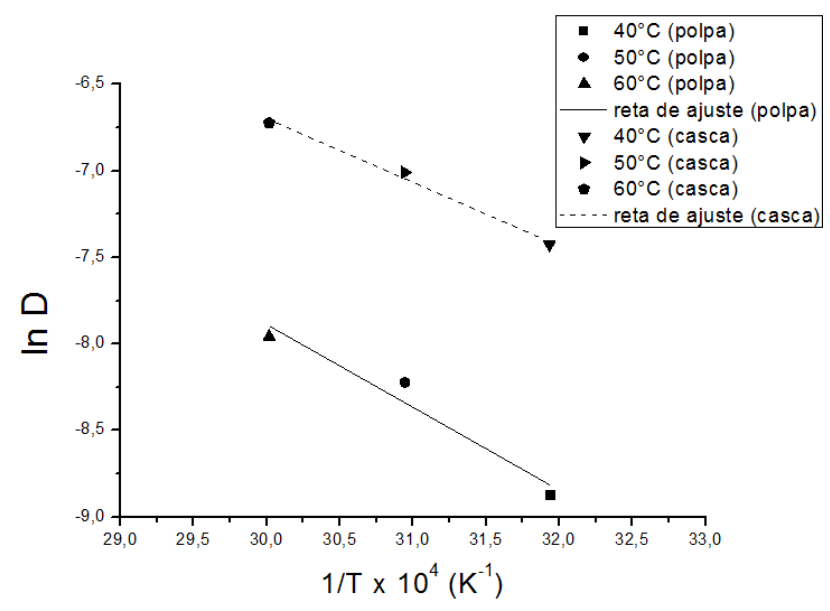

A energia de ativação $\left(E_{a}\right)$ calculada como a inclinação das retas obtidas está representada na Tabela 2, assim como a umidade final de secagem do produto. Observa-se que os valores da energia de ativação além de serem muito próximos foram extremamente baixos, comportamento esperado, pois a energia de ativação é influenciada pela taxa de transferência de calor que por sua vez é influenciada pelo tamanho de partículas e pela quantidade de massa a ser trabalhada (no caso as amostras possuíam 6,5 g de massa em 
triplicata). Segundo Martinazzo (2007), quanto menor for o tamanho das partículas, mais rápido acontece o aquecimento das mesmas (maior a taxa de transferência de calor) e menor a energia de ativação.

Tabela 2 - Valores da energia de ativação (E) obtidos para a casca e a polpa do abricó devido as diferentes taxas de temperatura de secagem.

\begin{tabular}{|c|c|c|}
\hline Abricó & $\begin{array}{c}\text { Energia de Ativação } \\
\left(\mathrm{KJ} \mathrm{mol}^{-1}\right)\end{array}$ & $\begin{array}{c}\text { Teor de umidade em } \\
\text { base seca }(X)(\mathrm{g} / \mathrm{g})\end{array}$ \\
\hline \hline Casca & 3,061 & 12,732 \\
\hline Polpa & 3,979 & 11,675 \\
\hline
\end{tabular}

Observa-se na Figura 2 que o erro máximo obtido, entre todos os vetores, para a casca foi de 1,516 e para a polpa foi de 1,216. Apesar destes valores, verifica-se que a modelagem da secagem da casca apresentou uma precisão média de -0,046 e para a modelagem de polpa, uma precisão média de 0,067, indicando uma baixa tendência de erro e uma previsão satisfatória da cinética de secagem a partir do modelo difusivo.

Figura 2 - Erro de ajuste versus dados experimentais para (a) casca e (b) polpa onde $(\square) 40^{\circ} \mathrm{C},(*) 50^{\circ} \mathrm{C} \mathrm{e}(\stackrel{\Delta}{*}) 60^{\circ} \mathrm{C}$

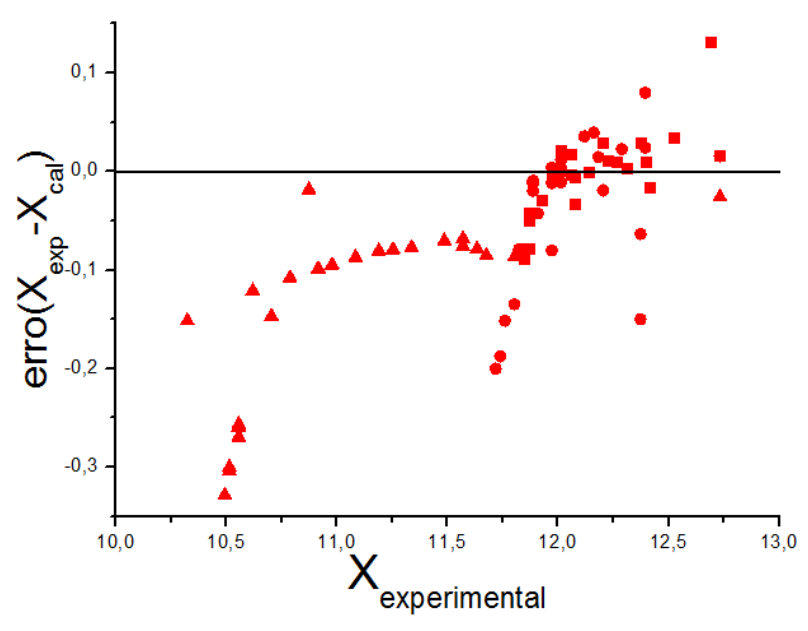

(a)

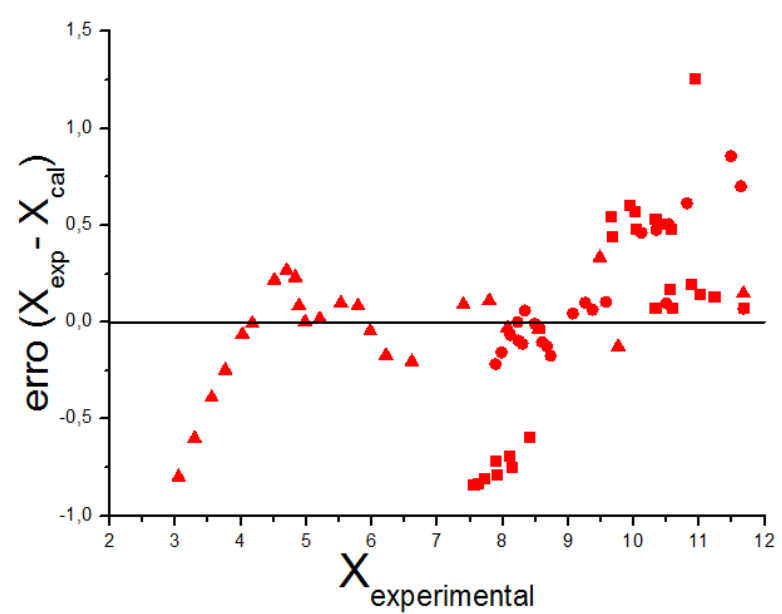

(b)

\section{CONCLUSÃO}

Foram obtidos valores da difusividade efetiva obtidos na secagem da casca e polpa do abricó nas temperaturas de 40,50 e $60^{\circ} \mathrm{C}$. No geral, a difusividade tendeu a aumentar com o aumento da temperatura do ar de secagem e a dependência do coeficiente de difusão em relação à temperatura foi descrita pela equação de Arrhenius. Os valores dos erros médios estão de acordo com o esperado, uma vez que para a casca apresentou-se um valor de -0,046 e para a polpa de 0,067 , os quais são valores inferiores a 0,1 . Finalmente, sugere-se realizar novos estudos cinéticos utilizando estes materiais, assim como as isotermas de dessorção para as mesmas temperaturas de estudo, com a finalidade de determinar o coeficiente difusivo em função da umidade de equilíbrio do sistema. 


\section{REFERÊNCIAS}

BRAGA, A. C. C.; SILVA, A. E.; PELAIS, A. C. A.; BICHARA, C. M. G.; POMPEU, D. R. Atividade antioxidante e quantificação de compostos bioativos dos frutos de abricó (Mammea americana). Alimentos e Nutrição, v.21, n.1, p. 31-36, 2010.

MARTINAZZO, A. P.; CORRÊA, P. C.; MELO, E. C.; BARBOSA, F. F. Difusividade efetiva em folhas de Cymbopogon citratus (DC.) Stapf submetidas à secagem com diferentes comprimentos de corte e temperaturas do ar. Revista Brasileira PI. Med. V. 9 , n. 1, p. 68-72, 2007.

MENON, A. S., MUJUMDAR, A. S. Drying of solids: principles, classification and selection of dryers. Handbook of Industrial Drying. New York: Marcel Dekker Inc., 1987.

PETRIN, N. Disponível em: http://beneficiosnaturais.com.br/abrico-beneficios-epropriedades-dessa-fruta/ Acesso em 29/11/2016.

RIZVI, S. S. H. Thermodynamic properties of foods in dehidration. Engineering properties of foods. New York: Marcel Dekker Inc, p. 389-391, 1986.

SILVA, D. C.; PESSOA, M. A.; LIMA, M. F.; VÉLEZ, H. A. V.; SANTANA. A. A. Estudo da modelagem de cinética de secagem da polpa de cupuaçu na produção de biopolímeros. $3^{\circ}$ Encontro Nordeste de Ciência e Tecnologia de Polímeros, Fortaleza, 2016.

VASCONCELOS, P. S. P. M. Compostos bioativos do abricó (Mammea americana), fruta da região amazônica brasileira. 2015. 143 f. Tese (Doutorado em Ciência de Alimentos) Faculdade de Engenharia de Alimentos, Universidade Estadual de Campinas, Campinas, 2015. 